\title{
Fracture in Phenolic Impregnated Carbon Ablator
}

\author{
Parul Agrawal* and Jose F. Chavez-Garcia ${ }^{\dagger}$ \\ ERC Corporation, NASA Ames Research Center, Moffett Field, California 94035 \\ and \\ John Pham \\ University Space Research Associates, NASA Ames Research Center, \\ Moffett Field, California 94035
}

DOI: $10.2514 / 1 . A 32389$

\begin{abstract}
This paper describes the development of a novel technique to understand the failure mechanisms inside thermal protection materials. The focus of this research is on the class of materials known as phenolic impregnated carbon ablators. It has successfully flown on the Stardust spacecraft and is the thermal protection system material chosen for the Mars Science Laboratory and SpaceX Dragon spacecraft. Although it has good thermal properties, structurally, it is a weak material. To understand failure mechanisms in carbon ablators, fracture tests were performed on FiberForm ${ }^{\circledR}{ }^{\S}$ (precursor), virgin, and charred ablator materials. Several samples of these materials were tested to investigate failure mechanisms at a microstructural scale. Stress-strain data were obtained simultaneously to estimate the tensile strength and toughness. It was observed that cracks initiated and grew in the FiberForm when a critical stress limit was reached such that the carbon fibers separated from the binder. However, both for virgin and charred carbon ablators, crack initiation and growth occurred in the matrix (phenolic) phase. Both virgin and charred carbon ablators showed greater strength values compared with FiberForm samples, confirming that the presence of the porous matrix helps in absorbing the fracture energy.
\end{abstract}

\section{Nomenclature \\ $a=$ length of crack, $\mathrm{m}$ \\ $K_{I}=$ stress intensity factor, $\mathrm{MPa} \sqrt{ } \mathrm{m}$ \\ $\sigma \quad=$ applied stress field, $\mathrm{Pa}$}

\section{Introduction}

$\mathbf{F}$ RACTURE in any system is a catastrophic event that system designers try to prevent. In spacecraft heat shields, it is of paramount importance as safety of the crew members and success of the mission is at stake, and it affects the planning for future missions. The Columbia disaster occurred due to mechanical damage to the thermal protection system (TPS) that could not survive the heating during reentry [1]. However, the study and analysis work involved with thermal protection materials is very complex. Many factors contributing to this complexity are: porosity of thermal protection materials, temperature-dependent mechanical and physical properties, and a combination of thermal and mechanical loads at various points in the trajectory. While arc-jet and other thermal-mechanical tests provide some understanding regarding the survivability of TPS materials [2,3], in-depth systematic studies of fracture toughness and failure mechanisms are required to optimize materials and predict the failure in TPS when subjected to a combination of thermalmechanical loads. Some researchers in the past have investigated the fracture characteristics of ceramic thermal protection tiles used

Presented as Paper 2011-3492 at the 42nd AIAA Thermophysics Conference, Honolulu, Hawaii, 27-30 June 2011; received 4 April 2012; revision received 5 September 2012; accepted for publication 23 September 2012; published online 5 June 2013. Copyright ( 2012 by the American Institute of Aeronautics and Astronautics, Inc. The U.S. Government has a royalty-free license to exercise all rights under the copyright claimed herein for Governmental purposes. All other rights are reserved by the copyright owner. Copies of this paper may be made for personal or internal use, on condition that the copier pay the $\$ 10.00$ per-copy fee to the Copyright Clearance Center, Inc., 222 Rosewood Drive, Danvers, MA 01923; include the code 1533-6794/13 and $\$ 10.00$ in correspondence with the CCC.

*Senior Research Scientist, Thermal Protection Materials and Systems Branch, MS 234-1. Senior Member AIAA.

'Research Scientist, Thermal Protection Materials and Systems Branch, MS 234-1.

"Student Intern, Thermal Protection Materials and Systems Branch.

${ }^{\S}$ Registered trademark of Fiber Materials Incorporated. in the Space Shuttle [4,5], however, to the authors' knowledge there has not been extensive research performed to study fracture toughness and failure mechanisms at a microstructural scale in ablating TPS materials. The research discussed in this paper is one of the first attempts to investigate failure mechanisms in ablators at a microstructural scale and provide an understanding that may lead to the development of structurally stronger materials. The present work focuses on investigating the failure mechanisms in the phenolic impregnated carbon ablator (PICA).

PICA is a logical choice for this research because it was the material used on the Stardust probe [6], is used on the SpaceX Dragon spacecraft," and will be used in the heat shield for the Mars Science Laboratory [7] mission. PICA was developed by scientists at NASA Ames Research Center in 1996 [8]. Although PICA has very good thermal properties, structurally it is a weak material, posing a challenge for the system designers to use it in the presence of mechanical loads and severe stresses. Several development efforts are underway to improve the structural properties of PICA without compromising the thermal properties or significantly increasing the density. The researchers at NASA Ames Research Center and Fiber Materials Incorporated (FMI) have been changing process parameters to alter the microstructure to improve mechanical properties [9-11]. To optimize the microstructure it is important to understand the mechanisms of crack initiation and propagation at a microstructure scale. In the present research the mechanical tests were performed on FiberForm (a precursor of PICA), virgin, and charred PICA, and crack propagation was investigated at a microstructural scale in each case. These tests also provided the data for estimation of fracture toughness, which can be later used for modeling of fracture as well as development of micromechanical failure models. The next section describes the microstructure of FiberForm, virgin, and charred PICA. Sections III and IV discuss the instrumentation and specimen design. Section V describes the test data and results. Summary and conclusions are provided in Sec. VI.

\footnotetext{
I"SpaceX Manufactured Heat Shield Material Passes High Temperature Tests Simulating Reentry Heating Conditions of Dragon Spacecraft," SpaceX press release, http://www.spacex.com/press.php?page=20090223, Hawthorne, CA, [retrieved 23 February 2009].
} 

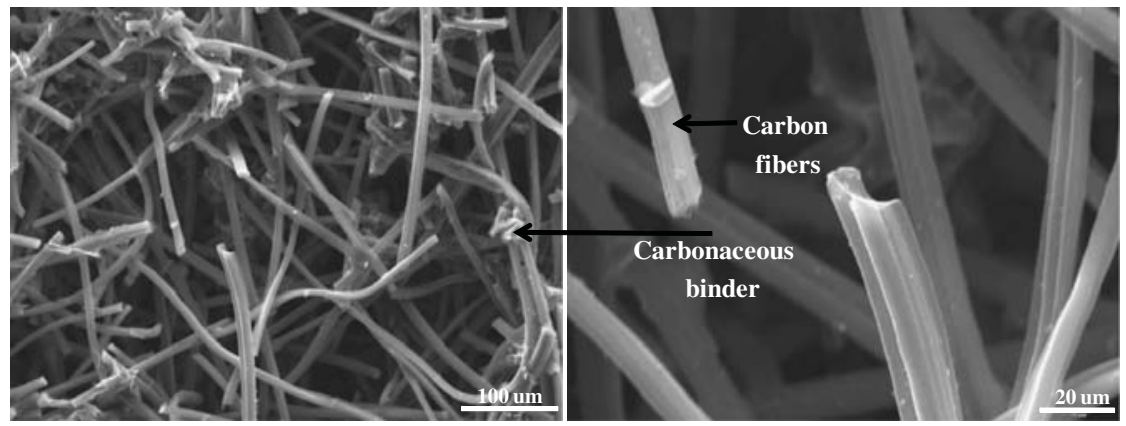

Fig. 1 Micrographs of FiberForm at different magnifications.

\section{Microstructure}

\section{A. FiberForm}

FiberForm is a low-density, very porous carbon fiber insulation material designed for high-temperature applications. It is processed at FMI and is the precursor substrate for processing PICA. Micrographs of FiberForm at different magnifications are shown in Fig. 1. It consists of a group of carbon fibers bonded to each other by means of an organic binder that is carbonized at very high temperature. After carbonization, all the organics evaporate and only a thin carbonaceous phase remains as the binder that holds the fibers together. The binder concentration varies, and in some regions there are smaller concentrations, while in other regions there are a fairly large group of fibers bound together. Some cross-linking that joins the fibers together and makes it a rigid preform also takes place during the processing. Each individual strand of carbon fiber consists of 5-6 individual fibers of diameter 5-6 $\mu \mathrm{m}$ that are joined together as shown in the higher-magnification micrograph of Fig. 1. The carbon fibers in FiberForm are oriented preferentially in one plane as a result of the manufacturing process, making it a transverse isotropic material with different material properties in the through-thethickness (TTT) and in-plane (IP) directions. The IP strength and stiffness of FiberForm is significantly higher compared with the TTT direction. This material was tested first in the IP direction to obtain the tensile strength and to understand the failure mechanisms.

\section{B. Virgin PICA}

As the name suggests, PICA is made by impregnation of phenolic resin within the FiberForm preform, followed by a cure cycle at an elevated temperature. It could be viewed as a two-phase material consisting of a network of carbon fibers and a very porous phenolic matrix dispersed on and in between the fibers as shown in Fig. 2. This highly porous structure makes it a low-density ablator. Due to the preferential orientation of carbon fibers in the FiberForm, PICA also displays transverse isotropic behavior with higher strength and stiffness in the IP direction compared with the TTT direction.

\section{Charred PICA}

Ablative TPS materials are subjected to very high heat flux during atmospheric reentry, causing them to pyrolyze and char. To understand the effects of phase changes due to pyrolysis, two types of charred PICA materials, furnace charred and arc-jet charred PICA, were studied. Furnace charred PICA samples were created by heating the specimens in a tube furnace to $1300^{\circ} \mathrm{C}$ in an inert environment. All the specimens were heated until they were uniformly charred. While all the organic material from the phenolic resin was evaporated, a thin carbonaceous matrix phase was still present between the carbon fibers. The arc-jet charred PICA samples were prepared by cutting the upper charred PICA layer of postarc-jet test samples. Micrographs of both arc-jet and furnace charred PICA materials are shown in Figs. 3a
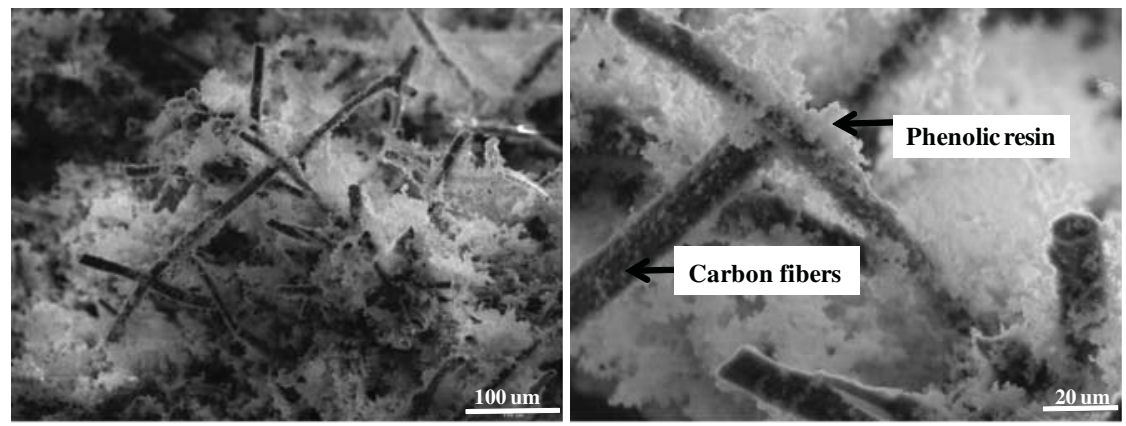

Fig. 2 Micrographs of PICA at different magnifications.
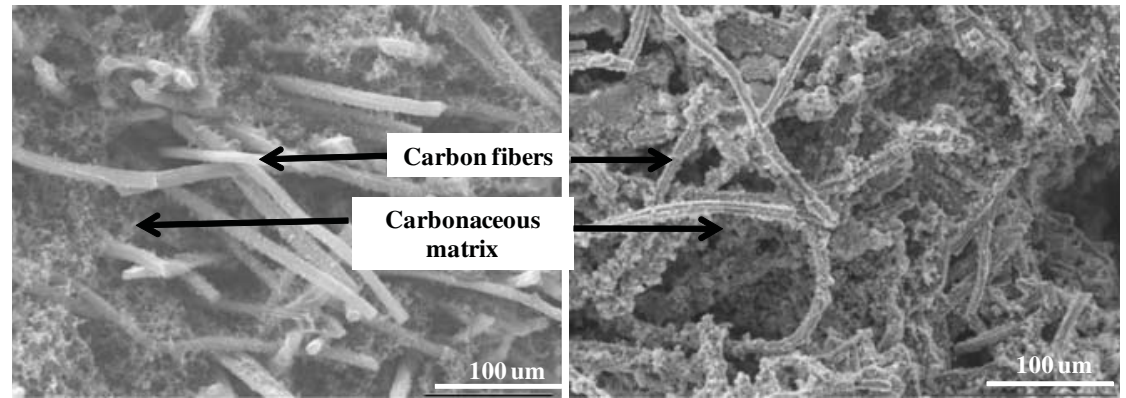

a)

b)

Fig. 3 Micrographs of a) arc-jet charred and b) furnace charred PICA. 


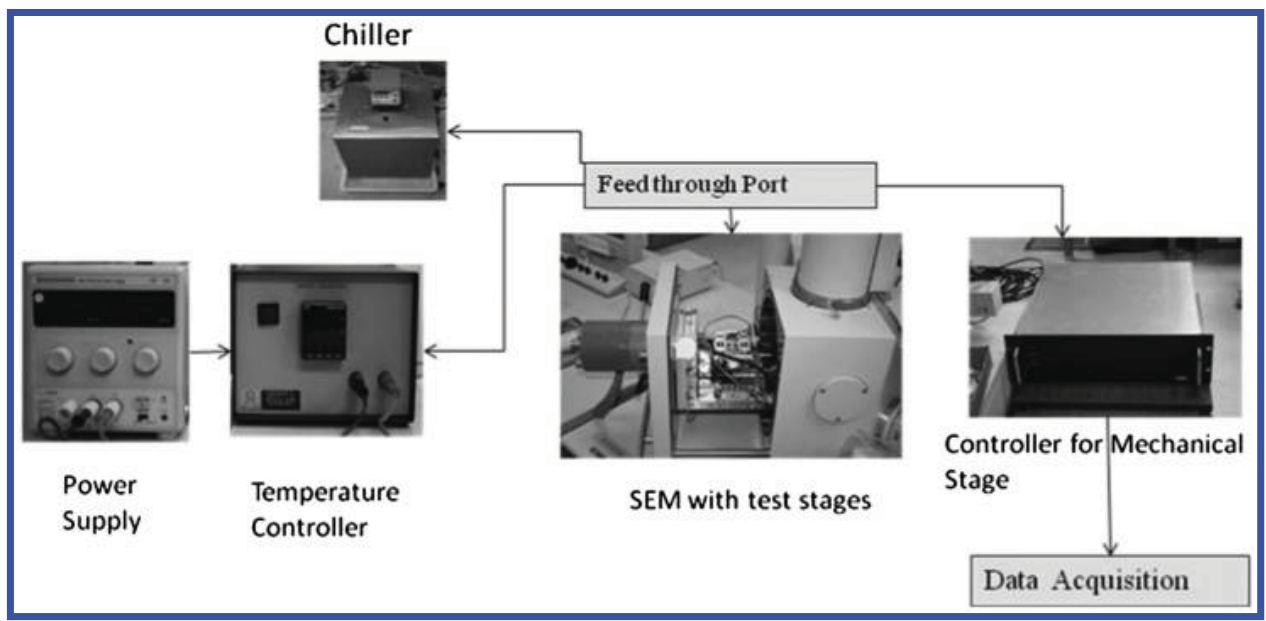

Fig. 4 Experiment setup for in situ SEM fracture experiments.

and $3 \mathrm{~b}$, respectively. Both materials show the presence of a porous and thin carbonaceous matrix phase dispersed between the carbon fibers. However, in the arc-jet charred PICA, the matrix on the top char layers is more sparse compared with the furnace charred PICA. This is caused by oxidation in the arc-jet environment. This phenomenon was also observed in the PICA char on the Stardust reentry probe [12].

\section{Experiment Design and Equipment}

The experiments were performed inside a Philips XL-30 electron microscope unit from FEI (Fig. 4). A miniature custom-designed mechanical stage was mounted inside the microscope chamber as shown in Fig. 5. A data acquisition system was integrated to the stage to acquire stress-strain data during the tests. The mechanical substage was driven by a small motor and could exert a tensile or compressive load of up to $5 \mathrm{kN}$ on a suitable test specimen. A strain transducer was mounted on the stage that provided the displacement measurements. The stage can accommodate a range of samples with dimensions varying from 20.0 to $60.0 \mathrm{~mm}$ in length, 5.0 to $15.0 \mathrm{~mm}$ in width, and 0.01 to $6.0 \mathrm{~mm}$ in thickness. These dimensions are ideal to obtain preliminary mechanical property data for an experimental material.

\section{Specimen Design}

Small samples of dimension $5.7 \times 1.0 \times 0.38 \mathrm{~cm}$ were cut from PICA billets and FiberForm blocks. Sample dimensions and drawings are shown in Fig. 6. To initiate fracture in a controlled manner and focus the electron beam to obtain high-magnification micrographs, fine notches were cut into the samples at the midline, using a microscriber tool. One of the notched charred PICA samples is shown in Fig. 7. Specimens were fabricated with and without notches for each FiberForm, virgin, and charred PICA material to compare the stressstrain behavior and IP tensile strength. The notches were nominally $1.27-2.54 \mathrm{~mm}$ in depth. The notch tip radius in most specimens was

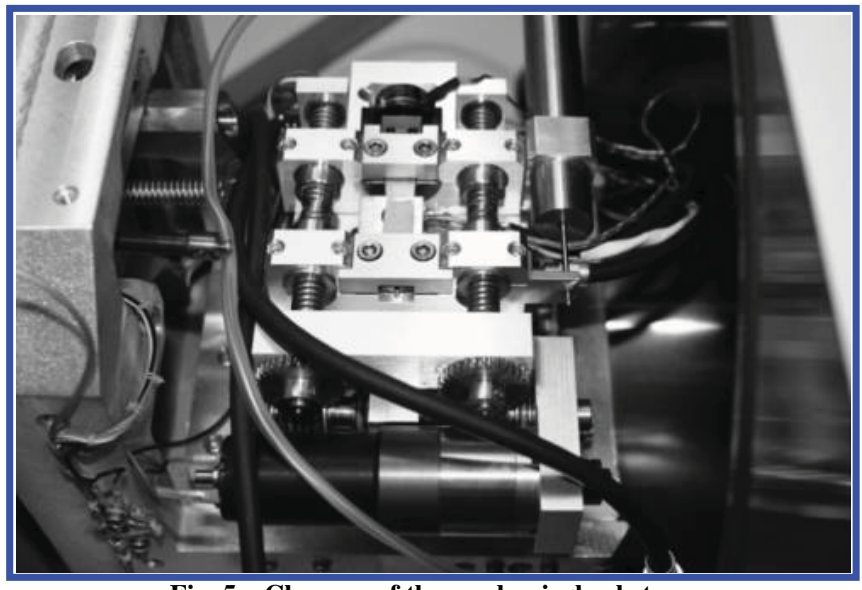

Fig. 5 Close-up of the mechanical substage. approximately $100 \mu \mathrm{m}$. These dimensions were sufficient to initiate crack at the notch tip and view the failure mechanisms in FiberForm and PICA. Thin aluminum tabs were glued to the ends of all the coupons with help of transfer coated RTV-560 (room temperature vulcanized) adhesive. This was required to avoid any local damage, slipping, and premature failure of specimens near the grips.

\section{Test Results and Analysis}

All the materials were tested at room temperature in the IP tension configuration as it is the stronger direction and it is easier to obtain the data. The samples were pulled inside the Scanning electron microscope (SEM) chamber under a high vacuum of 3.0e $-04 \mathrm{mBar}$. To obtain quasi-static conditions, the samples were pulled at a rate of $0.01 \mathrm{~mm} / \mathrm{s}$. The secondary electron mode detector was used to obtain high-quality micrographs. For notched samples, the electron beam was focused at the notch tip before tests. Several micrographs were obtained near the notch tip before the test to create a complete map near the notch at magnifications ranging from 25-100X. A video camera was connected to the microscope to capture the fracture in real time (30 frames/s). When a specimen was fractured, micrographs at various magnifications were obtained to observe the crack initiation and growth. Stress-strain data from the load cell and strain transducer were obtained at the same time using the data acquisition system. Some of the specimens were tested without notches to create a uniform uniaxial tension test configuration. While the primary objective of in situ SEM testing was to observe the failure mechanisms inside the TPS material, the stressstrain data obtained during these tests helped in understanding the influence of material flaws on the stress-strain relationship and providing some estimates for fracture toughness. Based on linear elastic fracture mechanics assumptions the stress intensity factor $K_{I}$ of a single-edge notched plate for a notch length $a$ and stress $\sigma$ is given by [13]

$$
K_{I}=1.12 \sigma \sqrt{\pi \quad a}
$$

Even though these materials are transverse isotropic, a rough estimate of fracture toughness can be provided based on Eq. (1). For some materials, like charred PICA, there are no tension test data available. The tension tests described here helped to obtain the IP tensile strength and toughness of charred PICA material. In-plane strength data for FiberForm, virgin, and charred PICA obtained during the tests

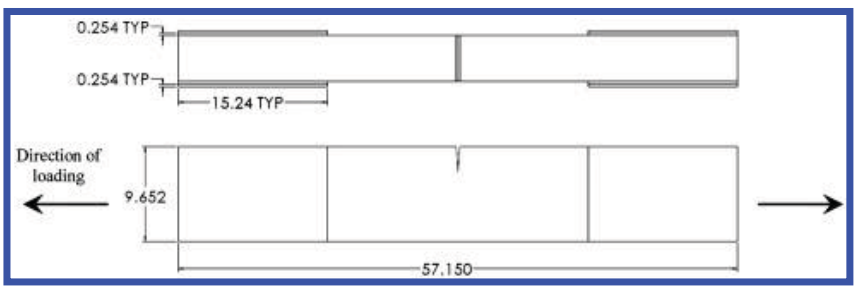

Fig. 6 Specimen geometry (dimensions in $\mathrm{mm}$ ). 


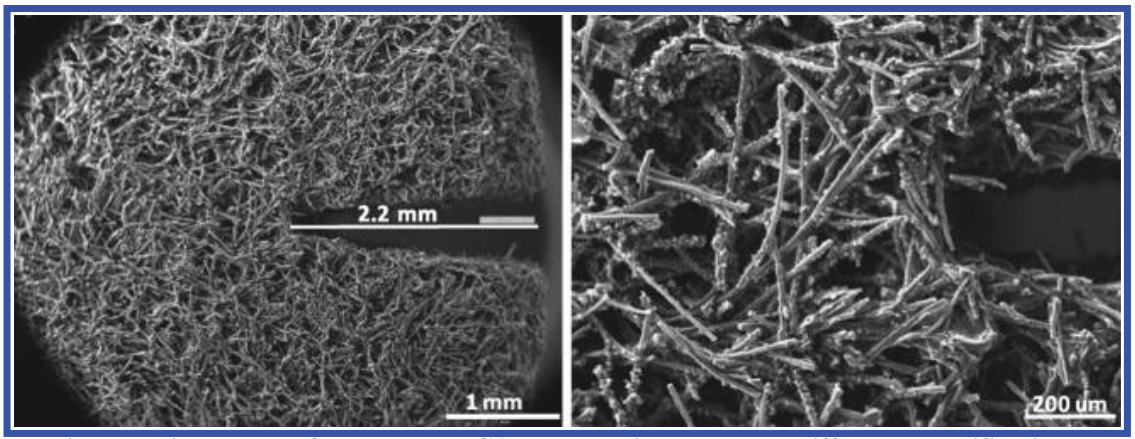

Fig. 7 Micrograph of a charred PICA coupon with a notch at different magnifications.

were compared with the Orion configuration managed (CM) crew exploration vehicle advanced development project material properties database values [14] to validate the tests and establish accuracy.

\section{A. FiberForm Fracture Tests}

Fracture tests were performed on eight notched and three unnotched FiberForm samples. The dimensions were kept constant across the samples to obtain consistent results. The notch depth in FiberForm specimens varied between 2.2 and $2.5 \mathrm{~mm}$. A $450 \mathrm{~N}$ load cell was used for these tests, because it provided more accurate information for smaller magnitude loads. For all the specimens with notches, cracks initiated and grew near the tip of notch. All the specimens fractured in a brittle manner as soon as they reached a critical tensile stress. The crack initiation was captured on video. Figure 8 shows the crack initiation near the notch tip in one of the specimens. By examining the videos and comparing pretest versus posttest micrographs, it can be seen that when the specimens reached a critical stress magnitude, the carbon fibers pulled away from the binder where it was in smaller concentration. Figure 9 shows the loss of binder material and Fig. 10 shows a micrograph of fiber separation

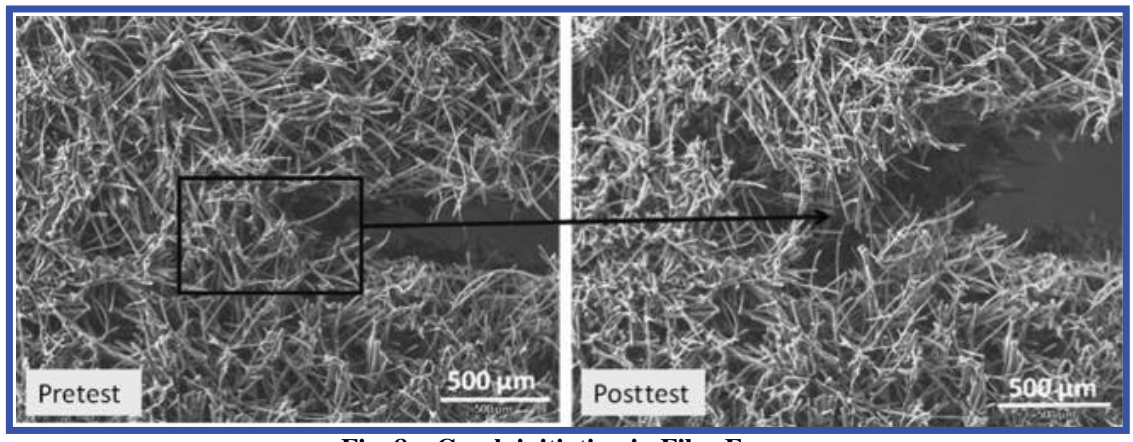

Fig. 8 Crack initiation in FiberForm.
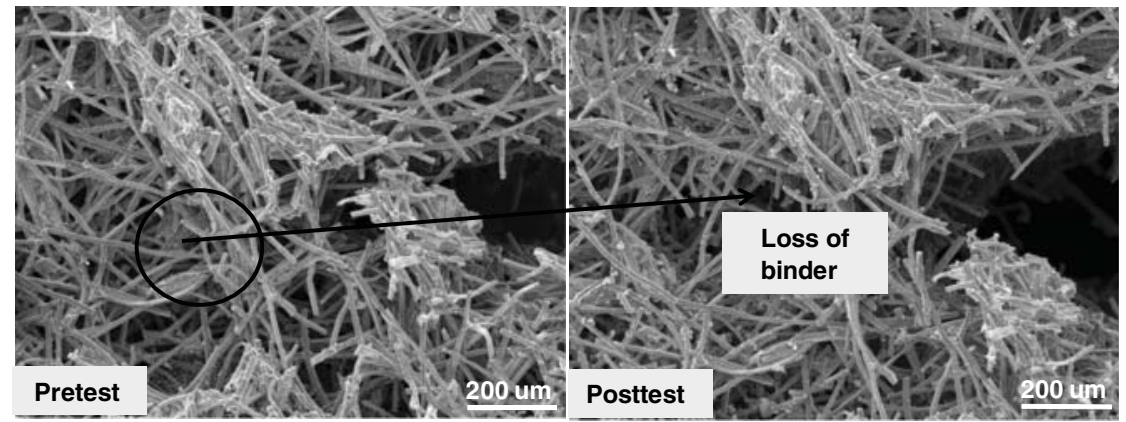

Fig. 9 Loss of binder where it is more sparse.

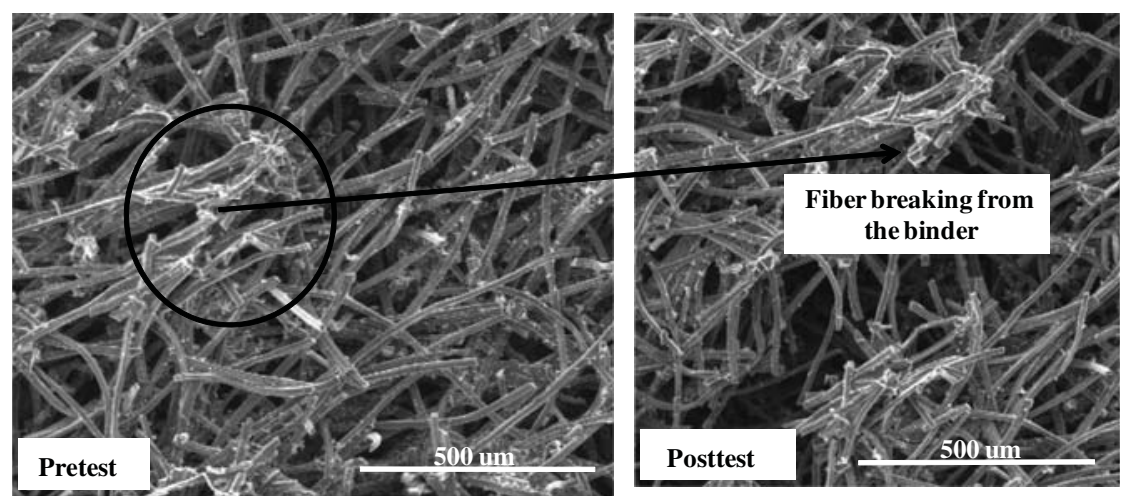

Fig. 10 Fiber separation near the binder. 
near the binder phase. Figure 11 also shows a magnified view of broken carbonaceous binder. Fiber breaking was not observed in any of the specimens. The tensile strength values and stress-strain data for representative unnotched and notched FiberForm coupons are shown in Fig. 12. All the specimens fractured in the range of $400-600 \mathrm{kPa}$ stress magnitude and presence of notches did not make a significant difference in tensile strength. This phenomenon is very different from a traditional dense material, and it will be important to take this into account when modeling fracture behavior of a porous material. The stress-strain curves obtained for these samples also suggested nonlinear stress-strain behavior from the very beginning. For most specimens, the strain-to-failure was between 0.6 and $1.0 \%$ and the mean stress at failure was around $440 \mathrm{KPa}$. Table 1 summarizes the average critical stress at failure and fracture toughness calculations based on Eq. (1) for several FiberForm samples that were tested with and without notches. There is not a significant difference between the samples with and without notches and both categories of samples fail at a similar stress values. The tensile strength data in the IP material direction is comparable to the data obtained on FiberForm in the CM database for the Orion program [14].

\section{B. Virgin PICA Fracture Tests}

Fracture tests were performed on both notched and unnotched virgin PICA samples. The dimensions were kept constant across the samples to obtain consistent results. Specimens were fabricated with

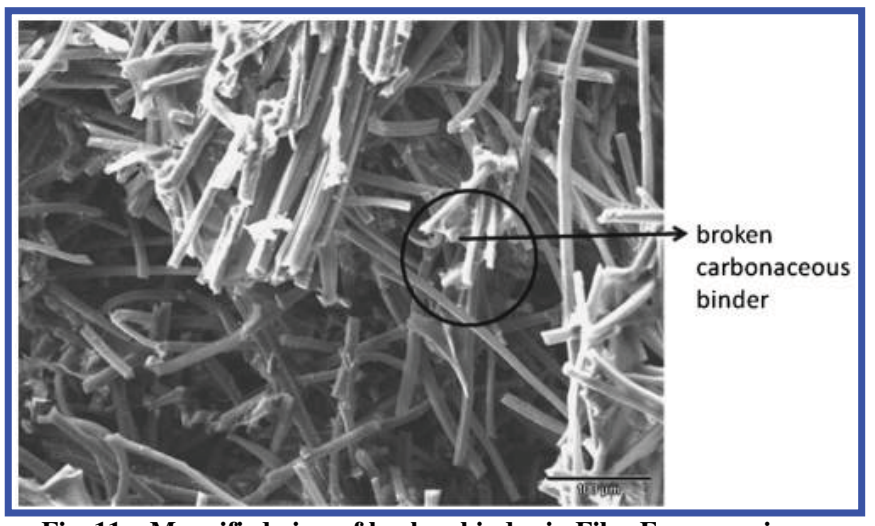

Fig. 11 Magnified view of broken binder in FiberForm specimen.
Table 1 Failure stress and fracture toughness calculations for FiberForm and PICA samples

\begin{tabular}{lrrcc}
\hline \multicolumn{1}{c}{ Sample } & Stress at failure, KPa & \multicolumn{2}{c}{$\begin{array}{c}\text { Fracture } \\
\text { toughness, } \\
\text { KPa* m }\end{array}$} \\
& & & Mt/2 \\
\hline FF no notch & 97.59 & 439.65 & - & - \\
FF notched & 68.87 & 443.62 & 7.32 & 42.46 \\
Charred PICA no notch & 237.77 & 776.31 & - & - \\
Charred PICA notched & 106.68 & 669.96 & 10.67 & 67.03 \\
Virgin PICA no notch & 169.02 & 1102.86 & - & - \\
Virgin PICA 1.27 mm notch & 17.16 & 1027.72 & 1.21 & 72.71 \\
Virgin PICA 2.54 mm notch & 168.25 & 692.78 & 16.83 & 69.31 \\
\hline \hline
\end{tabular}

two different notch sizes, 1.27 and $2.54 \mathrm{~mm}$, to investigate the effects of flaw size on strength and mechanical behavior. Similar to FiberForm, PICA specimens also fractured in a brittle fashion. Once specimens were at the critical stress magnitude, initiation and progression of cracks was rapid. Videos and micrographs capturing the crack initiation, and crack paths were obtained during the testing of multiple notched specimens. For notched PICA specimens, the cracks initiated in the porous matrix phase near the notch tip, as shown in Fig. 13. It progressed further in the phenolic matrix phase. The crack paths were governed by the presence of voids in the phenolic matrix phase. At various locations, crack bridging by carbon fibers as well as carbon fiber pullout was observed. One such example is shown in the posttest micrograph in Fig. 14.

Stress-strain data were obtained for all the specimens. The critical stress at failure for various notched and unnotched samples, as well as a representative stress-strain plot for an unnotched and $2.54 \mathrm{~mm}$ notched PICA sample, are shown in Fig. 15. Table 1 summarizes the average critical stress at failure and fracture toughness calculations based on Eq. (1) for several PICA samples that were tested with and without notches. The calculations based on Eq. (1) for estimated the room temperature fracture toughness of virgin PICA to be $72.0 \mathrm{KPa} \sqrt{ } \mathrm{m}$, about $40 \%$ higher than the FiberForm. The presence of a phenolic matrix phase made a significant difference in energy absorption in PICA. The critical stress of crack initiation and growth exceeded $1000 \mathrm{kPa}$, for samples without notches and the ones with smaller $(\sim 1.27 \mathrm{~mm})$ notches. This magnitude is about twice the magnitude compared with tensile strength in FiberForm samples.

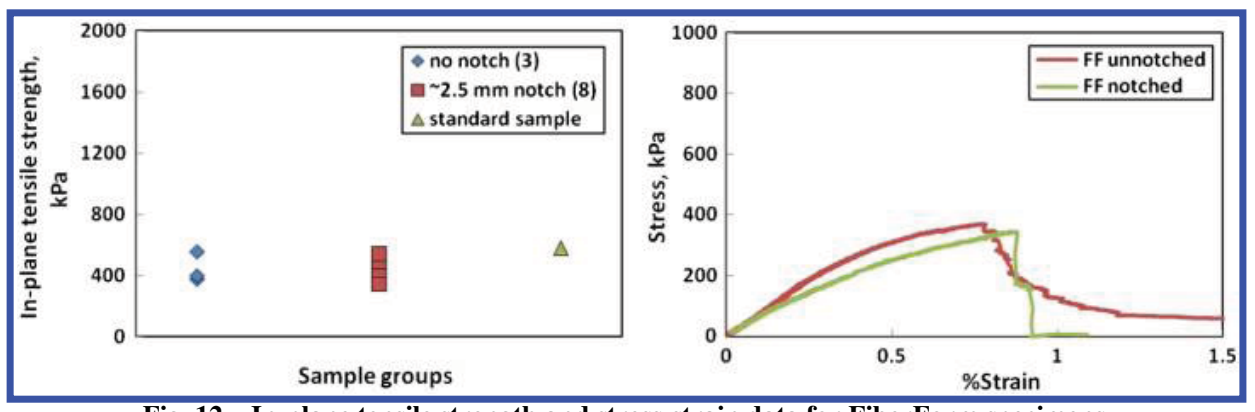

Fig. 12 In-plane tensile strength and stress-strain data for FiberForm specimens.
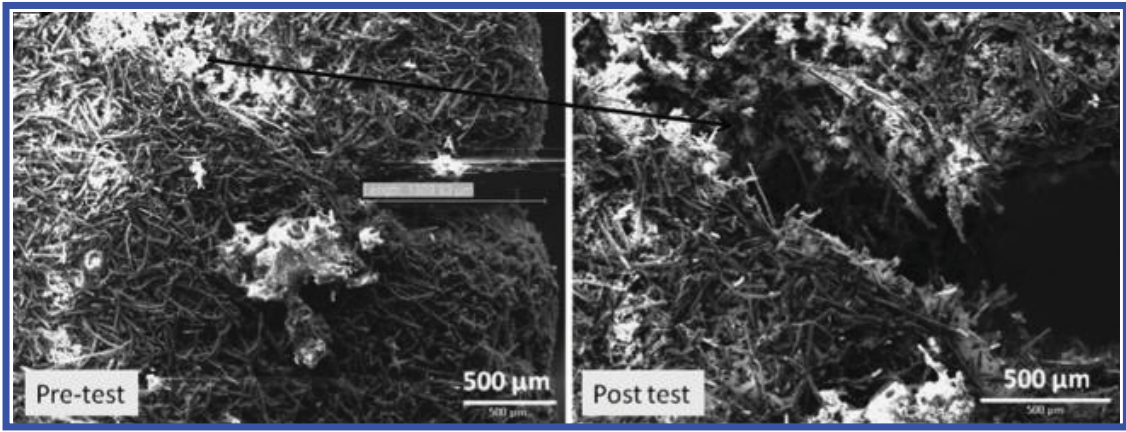

Fig. 13 Crack initiation in virgin PICA Specimen. 


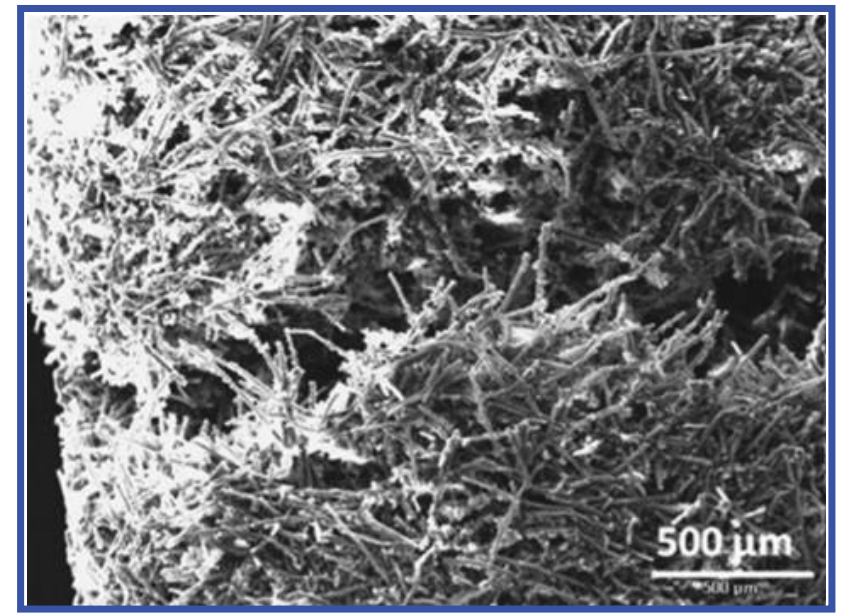

Fig. 14 Matrix cracking and fiber bridging in virgin PICA.

However, the samples with longer $(\sim 2.54 \mathrm{~mm})$ notches failed at lower values averaging $700 \mathrm{KPa}$. This shows that, unlike FiberForm, the presence of longer notches did reduce the tensile strength in virgin PICA. This is again an important aspect to consider when attempting modeling of porous materials and providing the critical stress values in the presence of flaws.

The specimens showed nonlinear stress-strain relation early on starting at $0.3 \%$ strain. The strain-to-failure for unnotched samples was in the range of $1.0-1.2 \%$ and tensile strength was in the range of $0.8-1.2 \mathrm{MPa}$, similar to the CM database values obtained during the tension test in the IP material direction for the Orion project [14]. The point to be noted here is that all PICA samples were made from a single billet. There is a significant density variation observed within the same billet as well as between different billets affecting the magnitude of strain-to-failure and tensile strength. The main objective of this research was to provide an insight into the failure mechanism, and not necessarily to provide the statistical estimates and ranges for mechanical properties like elastic modulus and stressto-failure. Therefore, the values mentioned in Table [1] should only be referred to as a guideline for providing the estimates for fracture toughness and critical stress-to-failure.

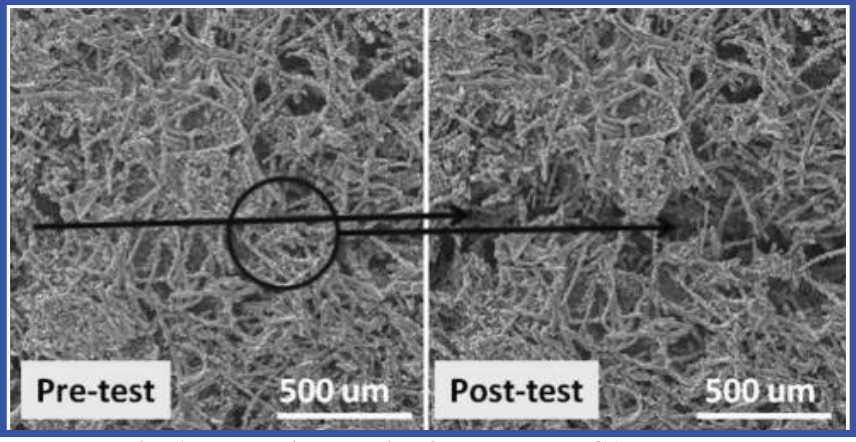

Fig. 17 Matrix cracking in charred PICA samples.

\section{Charred PICA Tests}

The charred PICA samples were prepared by two methods: charring the virgin material inside an inert furnace and sectioning pieces off of the charred portion of arc-jet tested PICA articles. Several furnace-charred PICA specimens with $\sim 2.54 \mathrm{~mm}$ notch size were tested inside the electron microscope. The crack initiation and growth was rapid once the critical stress was achieved, showing very similar behavior as virgin PICA samples. Videos and micrographs were obtained for the notched specimens. The crack initiated in the porous matrix phase and the crack path followed the porous matrix. Carbon particle shedding in the porous matrix was also observed in some videos. Fiber pullout and bridging phenomenons, similar to virgin PICA samples, were observed at some locations as shown in Fig. 16. Figure 17 shows the evidence of matrix cracking. Most specimens failed between 600 and $900 \mathrm{kPa}$. The charred PICA samples made from arc-jet articles showed similar behavior and tensile strength as the furnace char. Again, based on test data from most of the samples, the introduction of a notch did not make a significant difference in the maximum tensile stress at which failure occurred. The stress-strain data and tensile strength for representative samples are shown in Fig. 18. The maximum tensile stress achieved for these specimens was slightly higher than FiberForm samples, but lower than virgin PICA. Table 1 summarizes the mean critical stress at failure and fracture toughness estimates of charred PICA samples. The fracture toughness values for charred PICA at $67.0 \mathrm{KPa} \sqrt{ } \mathrm{m}$ is higher than FiberForm but only slightly lower than virgin PICA. This

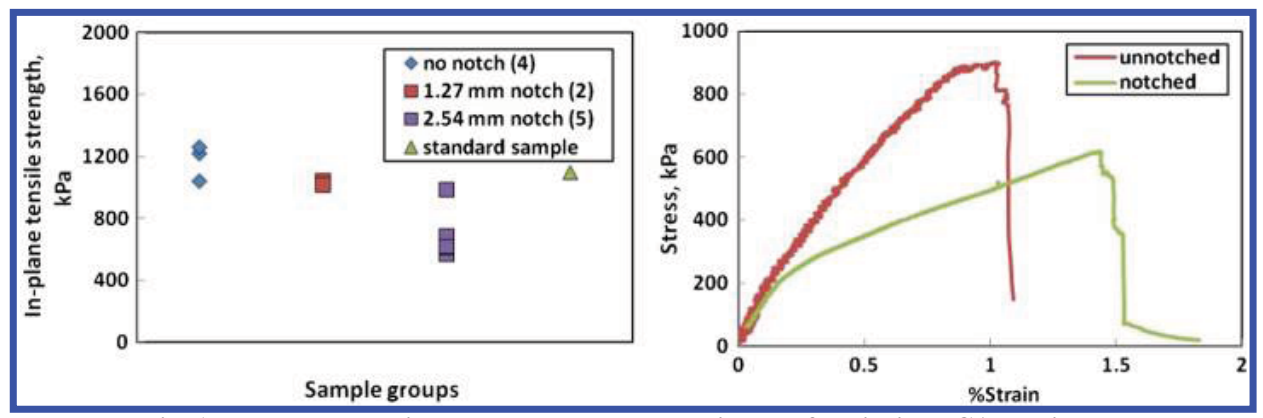

Fig. 15 In-plane tensile strength and stress-strain data for virgin PICA specimens.

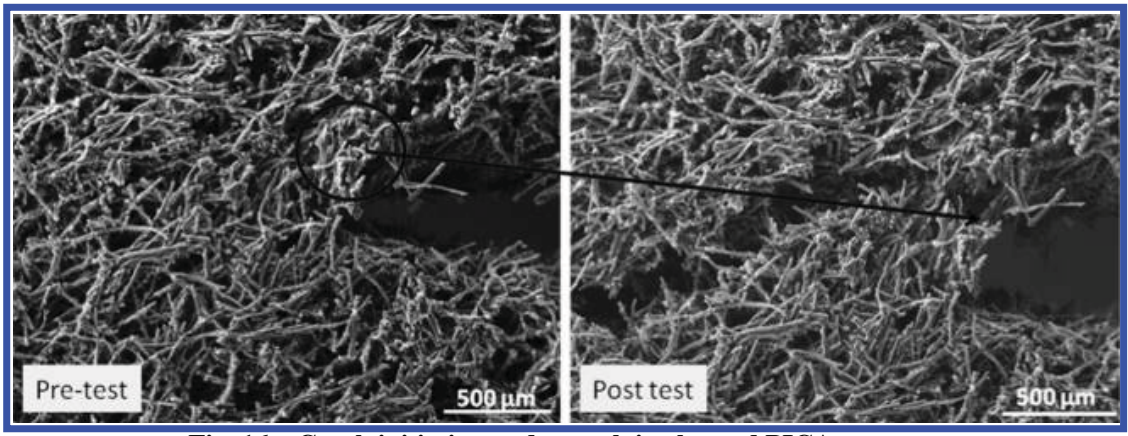

Fig. 16 Crack initiation and growth in charred PICA coupons. 


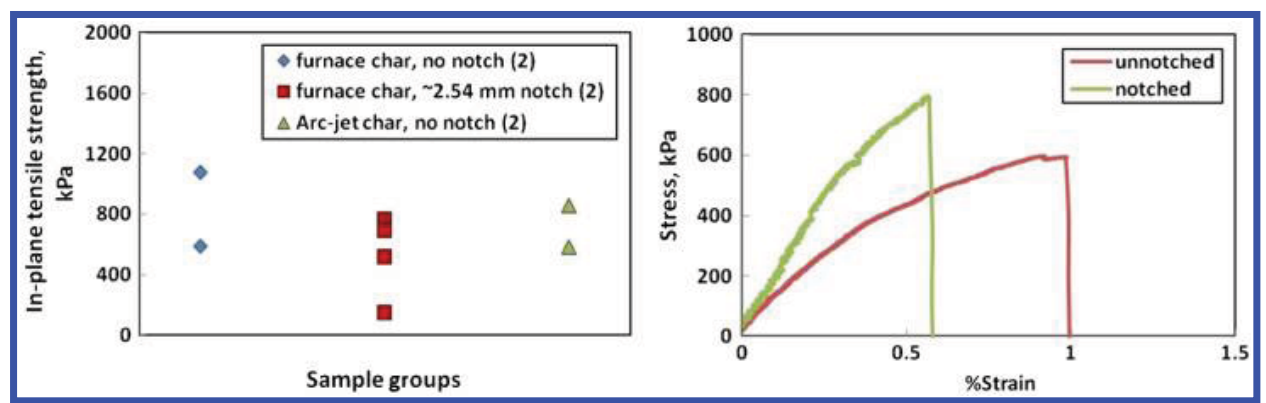

Fig. 18 In-plane tensile strength and stress-strain data for charred PICA specimens.

suggests that fracture toughness of the PICA ablator is driven by the extent of energy that can be absorbed by the porous matrix phase. The charred PICA specimens showed a similar nonlinear stress-strain relation as FiberForm and virgin PICA samples. However, the strainto-failure in charred PICA samples was lower than virgin PICA. To the best of our knowledge, to date no other tensile testing of charred PICA material has been conducted. This was the first test series where stress-strain plots and tensile strength data for the IP tension loading configuration were obtained.

\section{Conclusions}

Successful fracture testing of FiberForm, virgin, and charred carbon ablators inside an electron microscope was performed. This research proved that an investigation of failure mechanisms for thermal protection materials can be successfully conducted at a microstructural scale. The tests provided valuable insights into the failure mechanisms of these materials. For notched samples, the crack initiated and grew at the notch tip, and failure mechanisms in each of the materials were investigated at a microstructural scale by capturing videos of failure events and high-magnification micrographs. FiberForm specimens fractured due to fiber pullout from the carbonaceous binder wherever it was present in lower concentration. Occasional cracking of the binder was also observed where it was sparse. In virgin and charred carbon ablators, the fracture was governed by the cracking of the matrix phase. The phenolic matrix phase plays an important role in absorbing the energy, and the fracture toughness of the material is significantly influenced by the toughness of the porous phenolic matrix. The stress-strain data were obtained simultaneously for each test. The data suggest that, for small flaws, the stress at failure is not affected, and the stress distribution inside the sample is governed by the material porosity. However, for larger flaws the critical failure stress values start to decrease. The tensile strength magnitude in the in-plane material direction for FiberForm and virgin PICA ablator was comparable to the values obtained during bulk material testing using a universal test machine. The data suggest that this method can be very useful for obtaining reasonable estimates of the mechanical properties of charred ablators, including experimental thermal protection materials at a very early stage where fabrication of large samples may not be possible. This research can also provide very valuable information for computational modeling of the fracture of porous materials and micromechanical modeling of thermal protection materials.

\section{Acknowledgments}

The authors would like to acknowledge the support of the Exploration Technology Development and Demonstration Program managed at NASA Glenn Research Center. The work documented herein was performed as part of Exploration Technology Development and Demonstration Program's Entry, Descent, and Landing Technology Development Project, which is managed at NASA Langley Research Center and supported by NASA Ames Research Center, NASA Johnson Space Center, and the Jet Propulsion Laboratory. The authors gratefully acknowledge the support of element lead Robin Beck for the Entry, Descent and Landing
Thermal protection system (TPS) program, and Sylvia Johnson and Tom Squire for providing additional funds for this research. We also acknowledge support of Peter Fullam for design and fabrication of substages and support of summer intern Sammy Sabar. Finally, we acknowledge the NASA Space technology research and development (STRAD) contracts \# NNA10DE12C to ERC that made this work possible.

\section{References}

[1] "Columbia Crew Survival Investigation Report," NASA, Rept. SP2008-565, 2008

[2] Driver, D. M., Carballo, J., Beck, R., Prabhu, D., Santos, J., Cassell, A., and Skokova, K., "Arc Jet Testing in a Shear Environment for Mars Science Laboratory Thermal Protection System," AIAA Paper 20094230, 2009.

[3] Agrawal, P., Empey, D. M., and Squire, T. H., "Thermal-Structural Analysis of PICA Tiles for Solar Tower Test," AIAA Paper 2009-3755, 2009.

[4] Green, D. J., and Lange, F., "Micromechanical Model for Fibrous Ceramic Bodies," Journal of the American Ceramic Society, Vol. 65, No. 3, 1982, pp. 138-140. doi:10.1111/j.1151-2916.1982.tb10381.x

[5] Komine, A., and Kobayashi, A. S., "Interfacial-Fracture of Space Shuttle Thermal Protection System," Experimental Mechanics, Vol. 22, No. 12,1982 , pp. 454-461. doi:10.1007/BF02325423

[6] Willcockson, W. H., "Stardust Sample Return Capsule Design Experience," Journal of Spacecraft and Rockets, Vol. 36, No. 3, 1999, pp. $470-474$. doi:10.1007/BF02325423

[7] Lockwood, M. K., "Introduction: Mars Science Laboratory: The Next Generation of Mars Landers," Journal of Spacecraft and Rockets, Vol. 43, No. 2, 2006, p. 257. doi: $10.2514 / 1.20678$

[8] Tran, H., Johnson, C., Rasky, D., Hui, F., Chen, Y.-K., and Hsu, M., "Phenolic Impregnated Carbon Ablators (PICA) for Discovery Class Missions," AIAA Paper 1906-1911, June 1996.

[9] Fan, W., Thornton, J., Boghozian, T., Chavez, J., Stackpoole, M., Johnson, S., Olson, M., Gasch, M., Nikolaev, P., Maloney, P., Ghandehari, E., Arnold, J., and Cruden, B., "Strengthening PICA with Functionalized Carbon Nanotubes," NASA TM-2010-216388, 2010.

[10] Fan, W., Thornton, J., and Stackpoole, M., "Chemistry and Material Properties of a New Class of Lightweight Ablators," 35th Annual Conference on Composites, Materials, and Structures, USACA, Washington, DC, Jan. 2010.

[11] Dwyer, B., "Low-Temperature Preform Processing," FMI Technical Disclosure, Case \#, ARC 16638-1, March 2011.

[12] Stackpoole, M., Sepka, S., Cozmuta, I., and Kontinos, D., "Post-Flight Evaluation of Stardust Sample Return Capsule Forebody Heatshield Material," AIAA Paper 2008-1202, 2008.

[13] Anderson, T. L., Fracture Mechanics Fundamentals and Applications, 2nd ed., CRC Press, Boca Raton, FL, Chap. 2.

[14] Feldman, J., Alunni, A., and Stackpoole, M., "Thermal and Mechanical Property Testing Orion Heat Shield Candidates," 34th Annual Conference on Composites, Materials, and Structures, USACA, Washington, DC, Jan. 2010.

P. Gage

Associate Editor 